\title{
Eruptive Guidance of Permanent Teeth and Education of Oro-Facial Functions: Indications of Early Trainer Treatment
}

\author{
Ammouche $\mathrm{F}^{*}$ \\ MUHC Algiers, Algeria \\ *Corresponding author: Ammouche F, Department of Dentofacial Orthopedics, Mustapha University Hospital Center (MUHC), \\ Algeria
}

\begin{abstract}
The eruption of the permanent teeth is done in a harmonious way when the conditions of development of the dento-alveolar arches are all united. This is not always the case, obstacles to growth as lingual or orofacial dysfunctions, parafunctions or early extractions of temporary teeth can disrupt the eruptive process in permanent dentition. Functional education using trainer treatment can stimulate the development of the arches for proper teeth placement.
\end{abstract}

Keywords: Permanent teeth; Obstacles to growth; Eruptive process; Trainer treatment

\section{Introduction}

Functional orthodontic trainer use depends on its various indications. It allows the interception of orthodontic malocclusions, the contributions are numerous: It allows not only the functional education in case of orofacial dysfunctions (atypical swallowing, oral breathing and disorders of the mastication) but also the guidance of the eruption of permanent teeth by maintaining the space, stimulating the growth of the dentoalveolar arches and guiding teeth to a harmonious and balanced occlusion [1,2].

Studies have shown that these positive effects can be observed from the first months of wearing the device if the patient's compliance is complete [3-5]. Indeed, the best results depend on certain conditions of use. A daily wear is necessary for more than one year associated to a rigorous oral hygiene and breathing exercises.

The treatment should preferably be early during growth just before or at the time of the evolution of permanent teeth and maturation of orofacial functions. However, any anatomical or functional obstacle to breathing must be treated by otorhinolaryngologist before orthodontic treatment $[6,7]$.

\section{Materials and Methods}

Functional orthodontic trainer Multi T was used during 15-18 months. Its Characteristics are single size, dental silicone positioner, tongue tag, lip bumper, tooth channels and labial bows guide the erupting/ developing dentition into correct alignment.

Children were 9 years old in the mixed dentition with: dysfunctional habits (digital suction, swallowing problem, oral breathing), perimeter deficiency, narrow dental arches and disorders of dental eruption.

\section{The Diagnosis was based on}

a) Anamnese data

b) Examination of orofacial functions

c) Occlusal examination

d) Etiological analysis

e) Dental casts measurements

f) Photographic and radiographic analysis

g) Otolaryngology assessment

Patients with breathing problems were referred to the otolaryngologist for a medical report before orthodontic treatment. Indeed, the device is contraindicated when breathing is severely disrupted. It can aggravate the respiratory gene instead of improving it.The patients were told to use the appliance two 
hours and overnight during sleep associated to breathing exercises during daytime: nasal breathing, joined lips and swallowing the tongue guided by the appliance 10 to 15 times intermittently along the two hours.

\section{Results and Discussion}

After 15 months of treatment using a trainer the results showed:

a) Lingual repositioning;

b) Improvement of orofacial functions, in particular swallowing and breathing;

c) Deletion of digital suction

d) Improved shape and dimensions of the alveolar arches; e) Eruptive guiding of permanent teeth;

f) Improvement of dental relationship (incisor inclination, overbite, molar relationship);

g) Improvement of alveolar malocclusions;

After lingual repositioning, orofacial functions were improved, lip contact allowed nasal breathing and so, rapid effects on the shape, dimensions and relationships of the dento-alveolar arches in the three planes of space. The disturbed dental eruption $[4,13]$ before treatment has been reduced, results showed a correct alignment concerning both anterior and posterior teeth (Figure 1 \&2).

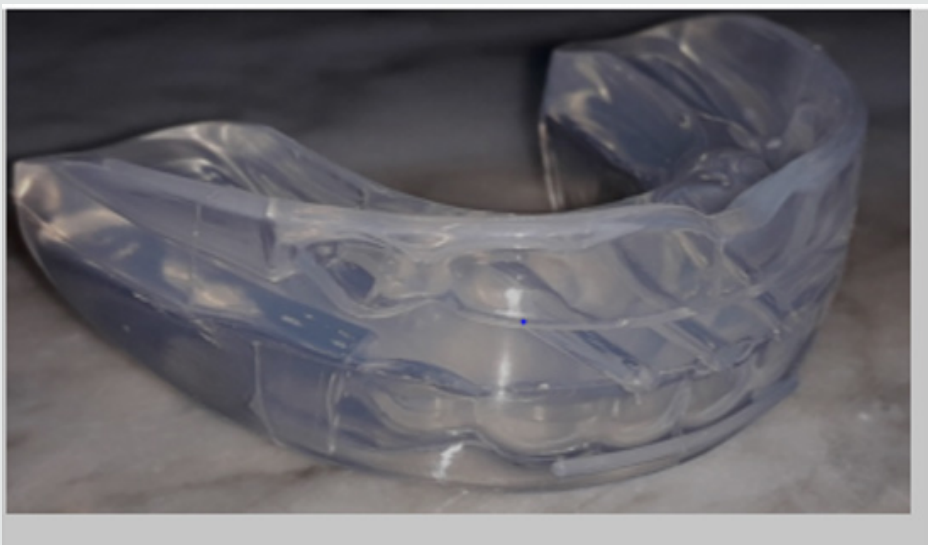

Figure 1: Multi T Orthodontic trainer.

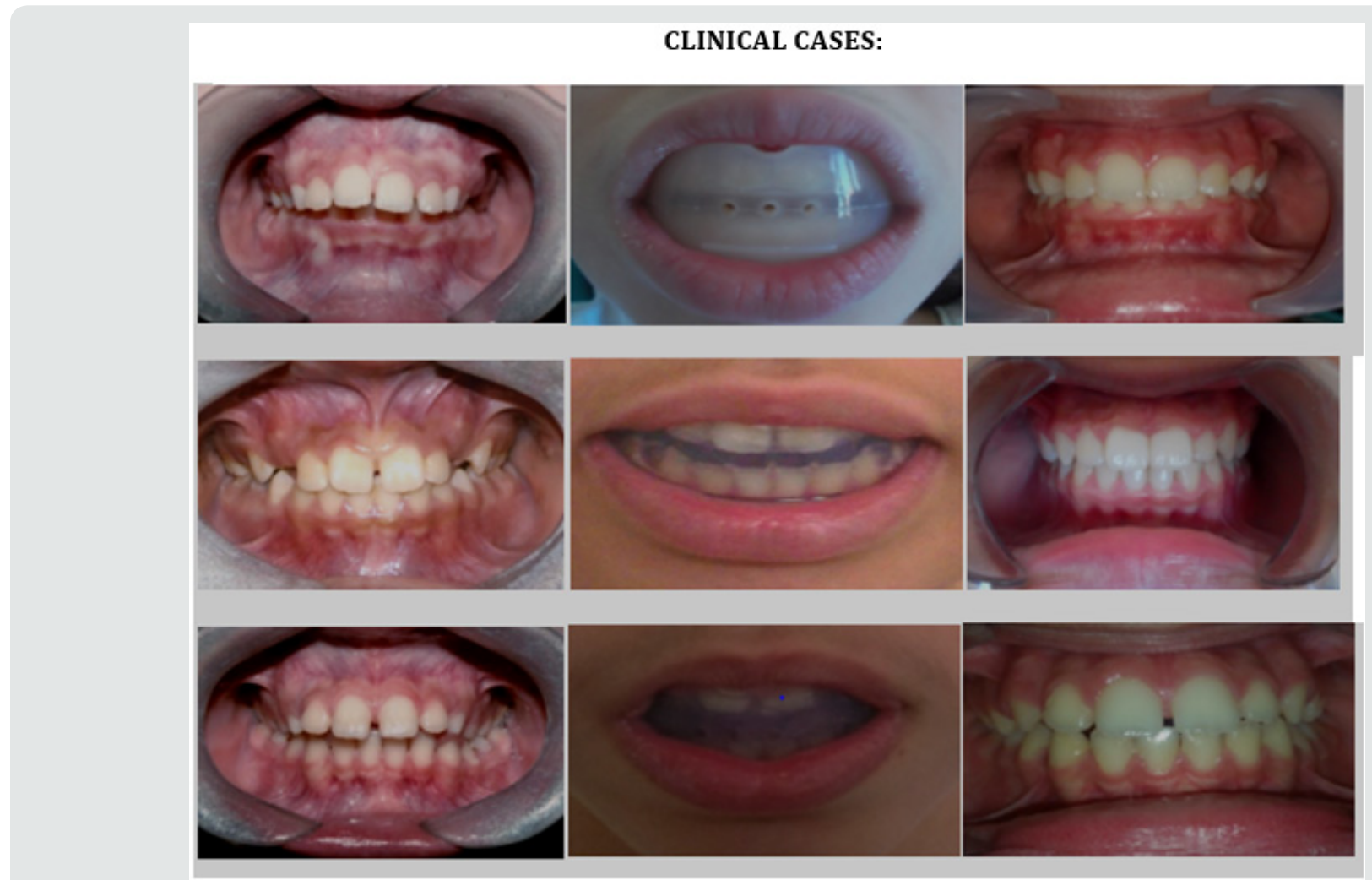

Figure 2: Functional and dentoalveolar modifications after using myofunctional device. 
The trainer allowed the interception of functional and dentoalveolar anomalies in a relatively short time in compare with the devices usually used. Moreover, in most cases, it wasn't necessary to use another device to improve the results; this has reduced the costs of treatment. Previous studies in Picaud [10] reported same positive effects on growth and dental eruption but there is a limitation when using the appliance, it concerns the lack of compliance in some cases. This must be taken into account from the beginning of treatment in order to decide whether to use or not a myofunctional appliance. It seemed important to us to highlight the possibilities offered by this device to correct orthodontic malocclusions before their aggravation, the ideal is to act quickly and when possible on several anomalies at the same time. The goal is to optimize treatment as much as possible as showed by Usumez et al. [11] and Tallgren et al. [12].

During the phases of temporary and mixed dentition and therefore active growth, orofacial functions play a major role in the development of the dentoalveolar arches $[8,9,14]$. Screening and early diagnosis as well as the use of adapted devices helps to restore the necessary balance in case of dysfunctions for a correct placement of the permanent teeth. The usual devices usually have only one function and must be replaced as the treatment progresses, as opposed to the trainer device that can correct several anomalies simultaneously, thus reducing the duration and the cost of the treatment.

\section{Conclusion}

The various orofacial dysfunctions have been until very recently supported by devices that are inefficient or limited action, with no significant effects on growth and dental eruption. The trainer is a good alternative, it is preformed but in different shapes and sizes according to the age and the anomaly. It can be used associated to a fixed therapy but its action during temporary or mixed dentition gives impressive results. It is the best device for prevention and interception of malocclusions. The positive effects are also expressed both on the duration and on the costs of treatment provided.

\section{References}

1. Ammouche F (2017) Possibilités offertes par la rééducation fonctionnelle dans la prise en charge orthodontique préventive et interceptive. Santé Publique 29: 3 .

2. Aznar T, Galan AF, Marın I, Domınguez A (2006) Dental Arch Diameters and Relationships to Oral Habits. Angle orthod 76(3): 441-445.

3. Beressi E (2009) Éducation fonctionnelle dans un service clinique hospitalo-universitaire. Orthodontie bioprogressive. 23-32.

4. Fernandez CCA, Pereira CVCA, Luiz RR, Vieira AR, Costa MDC (2018) Dental anomalies in different growth and skeletal malocclusion patterns. Angle orthod 88(2): 195-201.

5. Gipch J (2012) Lorthopédie fonctionnelle et les éducateurs fonctionnels souples: évolutions ou révolutions? Info Dentaire (29-30): 4-14.

6. Gola R, Richard O, Cheynet F, Brignol L, Guyot L (2006) Étiopathogénie de l'obstruction nasale et conséquences sur la croissance maxillofaciale. EMC 2006 Elsevier SAS (23-474-C-10): 1-17.

7. Kadner A (1925) Etiology of the anomalies of the teeth and a new and simplified method of treatment on the basis of the knowledge of etiology. AJO-DO 11(7): 635-646.

8. Lacout J, Deroze D (2009) La prévention en orthopédie dento-faciale. Ortho autrement 1: 6-13.

9. Patti A, Perrier D Arc G (2005) Clinical Success in Early Orthodontic Treatment. Quintessence Publishing, France 17: 756-757.

10. Picaud M (2010) L'éducation fonctionnelle au cabinet d'orthodontie à l'aide d'appareils amovibles souples. Thèse pour le Diplôme d'état de Docteur en chirurgie dentaire. Université Nantes p. 156.

11. Usumez S, Uysal T, Sari Z, Basciftci FA, Karaman AI, et al. (2004) The effects of early preorthodontic trainer treatment on Class II, Division 1 Patients. Angle Orthod 74(5): 605-609.

12. Tallgren A, Christiansen RL, Ash M, Miller RL (1998) Effects of a myofunctional appliance on orofacial muscle activity and structures. Angle Orthod 68(3): 249-255.

13. F Vaysse, E Noirrit, I Bailleul Forestier, A Bah, D Bandon (2010) Les anomalies de l'éruption dentaire. Eruption and teething complications. Archives de pédiatrie 17(6): 756-757.

14. Warren J, Bishara S, Steinbock K, Yonezu T, Nowak A (2001) Effects of oral habits' duration on dental characteristics in the primary dentition. J Am Dent Assoc 132(12): 1685-1693.

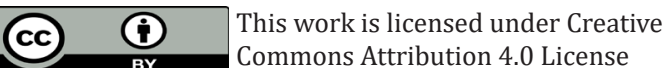

To Submit Your Article Click Here: Submit Article

DOI: $10.32474 / M A D O H C .2019 .03 .000175$

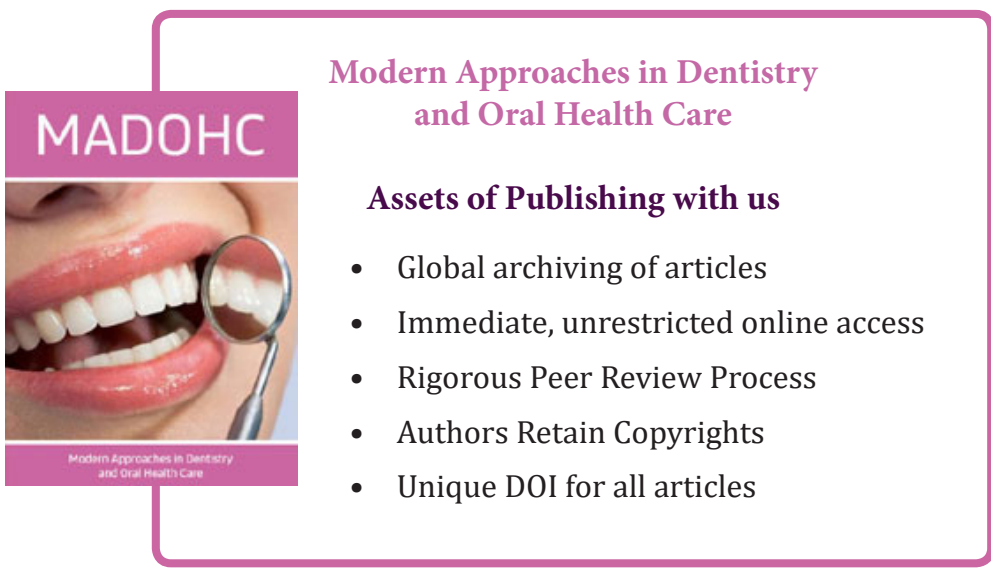

